\title{
Personality traits influencing somatization symptoms and social inhibition in the elderly
}

This article was published in the following Dove Press journal:

Clinical Interventions in Aging

13 January 2014

Number of times this article has been viewed

\section{Tinakon Wongpakaran Nahathai Wongpakaran \\ Faculty of Medicine, Chiang Mai University, Chiang Mai, Thailand}

Correspondence: Tinakon Wongpakaran Department of Psychiatry, Faculty of Medicine, Chiang Mai University, I 10 Intawarorot Rd, Tambon Sriphum, Amphur Muang, Chiang Mai,

Thailand, 50200

Tel +66 53945422

Fax +66 53945426

Email tinakon.w@cmu.ac.th
Purpose: Somatization is a common symptom among the elderly, and even though personality disorders have been found to be associated with somatization, personality traits have not yet been explored with regard to this symptom. The aim of this study is to investigate the relationship between personality traits and somatization, and social inhibition.

Patients and methods: As part of a cross-sectional study of a community sample, 126 elderly Thais aged 60 years or over completed self-reporting questionnaires related to somatization and personality traits. Somatization was elicited from the somatization subscale when using the Symptom Checklist SCL-90 instrument. Personality traits were drawn from the 16 Personality Factor Questionnaire and social inhibition was identified when using the inventory of interpersonal problems. In addition, path analysis was used to establish the influence of personality traits on somatization and social inhibition.

Results: Of the 126 participants, $51 \%$ were male, $55 \%$ were married, and $25 \%$ were retired. The average number of years in education was 7.6 (standard deviation =5.2). "Emotional stability" and "dominance" were found to have a direct effect on somatization, as were age and number of years in education, but not sex. Also, $35 \%$ of the total variance could be explained by the model, with excellent fit statistics. Dominance was found to have an indirect effect, via vigilance, on social inhibition, which was also influenced by number of years in education and emotional stability. Social inhibition was not found to have any effect on somatization, although hypothetically it should.

Conclusion: "Emotional stability", "dominance", and "vigilance", as well as age and the number of years in education, were found to have an effect on somatization. Attention should be paid to these factors in the elderly with somatization.

Keywords: trait, mediator, neuroticism, somatization

\section{Introduction}

Somatization is a condition in which the patient experiences unexplained medical symptoms, and is sometimes called "functional somatic complaint". 1,2 The condition is particularly hard to detect in the elderly and its effects should not be underestimated as it can become a serious medical condition. ${ }^{3}$ High comorbidity between medically unexplained physical symptoms and other psychiatric disorders has been found among elderly patients. ${ }^{4}$ One survey revealed that general practitioners believe somatization to be an important cause of physical complaints among the elderly, ${ }^{5}$ and some investigators found that it is difficult to differentiate between the functional somatic and psychiatric origins of somatic complaints, in particular if they are overlapping. ${ }^{6}$ 
Somatic symptoms may be related to depression, as depressed elderly people commonly manifest their suffering through physical symptoms. ${ }^{78}$ In previous studies, we showed that depressed elderly people tend to express their frustrations more as physical symptoms than nondepressed individuals, and that this was more the case in elderly depressed than younger depressed people. ${ }^{9,10}$ In addition, other factors such as culture, education, social values, or even ageism make it difficult for elderly people to be open or assertive, and as a result, physical complaints would seem to be a coping mechanism that they use to deal with this inner conflict. ${ }^{11}$

Somatic symptoms may present themselves differently due to the influence of ethnic factors. For example, South Americans have been found to have the highest rates of somatization ${ }^{11,12}$ and the condition is also common in Asian people, especially among those who are experiencing depression, regardless of their age. ${ }^{13}$ An ethnic difference has also been found in terms of the types of symptoms reported. For instance, one symptom described as a "heavy head" is significantly more common among Asians than among Americans, Caucasians, and Africans. ${ }^{11}$ It may be that culture and ethnic background frame how individuals express themselves, whether they benefit or look bad when coping with types of stress or conflict, and in certain situations. For example, in Thai society, elderly people are expected to have higher moral standards than younger people, so it may be unacceptable to express feelings such as sexual desire, even with a doctor, even if they still have them.

Somatic symptoms, on some levels, may also be related to personality traits such as neuroticism. Neuroticism is the actual inclination to see distressing thoughts easily, such as frustration, anxiety, depressive disorder, or susceptibility. It is also at times referred to as "emotional instability", "inverse emotional stability", or "negative affectivity". Neuroticism has been found to be one of the strongest predictors of somatism, ${ }^{14}$ and alexithymia is another personality trait that is found to have an influence on the condition. ${ }^{15,16}$ Based on these results, somatization is viewed psychoanalytically as a defense mechanism against internal conflict whereby an individual finds it difficult to express himself or herself directly. ${ }^{17}, 18$ It is also influenced by age and culture, and as mentioned before, can be viewed as a repository for frustration. Moreover, hypothetically, somatization should be prominent in individuals who display social inhibition, meaning it is difficult for them to effectively access help from others or express themselves directly. ${ }^{19}$ Social inhibition is thought to reflect complex interpersonal behavior that is related to social withdrawal, regardless of whether it is related to anxiety, depression, or even apathy. ${ }^{20-22}$ Social inhibition, however, as measured by the interpersonal inventory of interpersonal problems, tends to be viewed as a trait rather than as a symptom. ${ }^{23}$

Therefore, with regard to the role of social inhibition, in theory it is believed to act as a link or mediator between personality traits and somatization, and previous studies have found a correlation between it and somatization, although mostly accompanied by the presence of negative affectivity (or neuroticism). ${ }^{19,24-26}$

However, little is known about the relationship between somatization and social inhibition in the elderly, in whom somatization is a common condition. We were interested in studying the relationship between these variables, as well as personality traits in addition to neuroticism. This study, therefore, aimed to explore the effects of personality traits on somatization and social inhibition as well as some sociodemographic data, based on the hypothesis that personality traits have either a direct effect on somatization, or indirectly via social inhibition (Figure 1). These have not previously been investigated.

\section{Materials and methods}

This study was part of a wider study conducted in $2009^{27}$ which was approved by the Ethics Committee at the Faculty of Medicine, Chiang Mai University.

\section{Participants}

The authors analyzed the data of 126 elderly participants who provided demographic data and who completed the Inventory of Interpersonal Problems (IIP-64), ${ }^{27,28}$ the Sixteen Personality Factor (16 PF), and Symptom Checklist (SCL)-90 29,30 questionnaires.

\section{Instruments}

Demographic data concerning the sex, age, income, and education of the participants were obtained. Participants aged 60 years or more were recruited (in Thailand, people over 60 years old are defined as elderly). Income was assessed based on the gross monthly household incomes of the participants ( $<1$ unit to 9 units, 1 unit equals 5,000 baht or 167 US dollars). The number of years spent in education was also used in the analysis.

The IIP- $64^{28}$ is a self-reporting questionnaire which measures interpersonal difficulties across eight subscales as follows: domineering, vindictive, nonassertive, socially inhibited, overly accommodating, self-sacrificing, and intrusive/needy. The scale consists of 64 items which are rated on a 5-point scale, ranging from 0 (not at all) to 4 (extremely), 


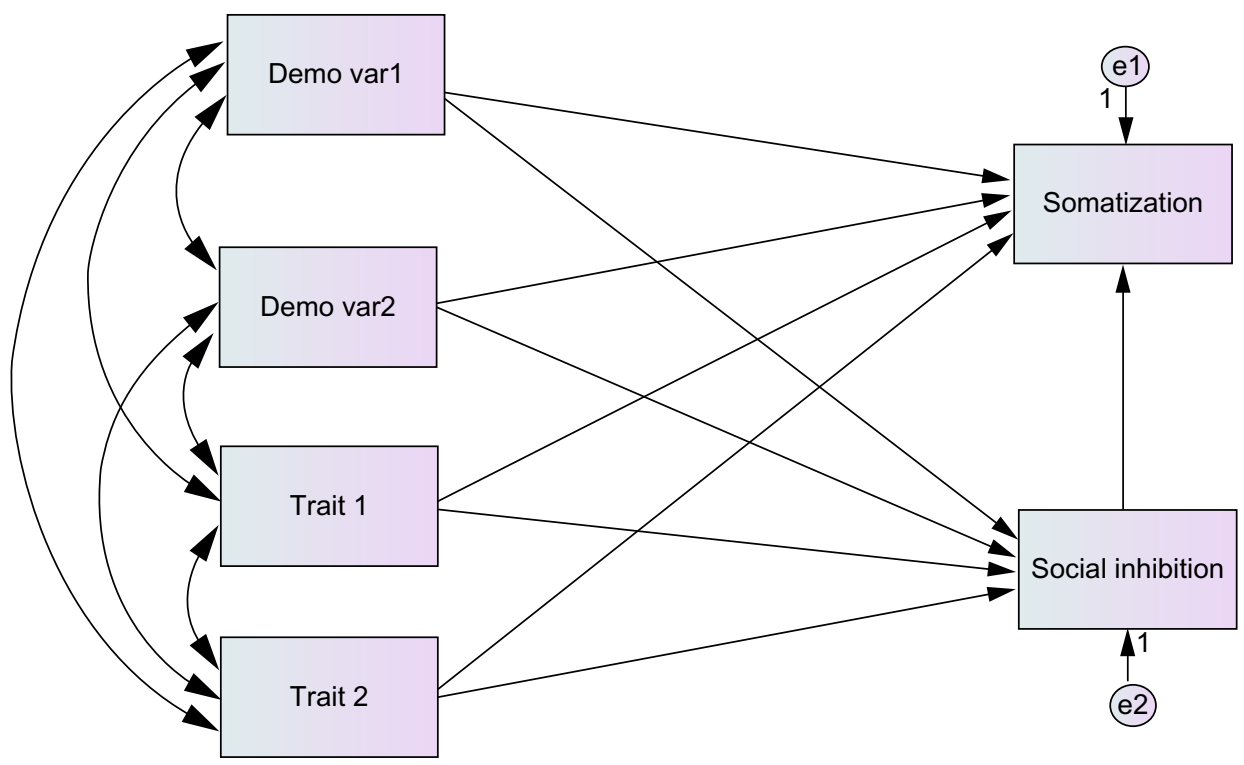

Figure I Hypothesized path model. The proposed path analysis model of the mediation effects explaining the personality traits, demographic variables, social inhibition and somatization. The lines with arrow heads show the direction of the path coefficients.

Abbreviations: Demo var, demographic variable; el, error term of somatization; e2, error term of social inhibition.

and the subscales can be modeled geometrically, as with a circumplex model. Each subscale signifies an octant in this model. The Thai version has demonstrated a good overall internal consistency of $\alpha=0.95 .{ }^{27}$ The test-retest reliability of the IIP-64 subscale using intraclass correlation coefficient (ICC) ranged from 0.68 to 0.76 and 0.81 for the total score, although only the subscale "socially inhibited" $(\alpha=0.79)$ was used for the analysis. The IIP-64 tool also revealed a factor structure in accordance with the circumplex property.

\section{The somatization dimension of the SCL-90}

The SCL- $90^{29,30}$ is a 90 item self-reporting questionnaire used to assess psychological problems and symptom distress. Each item assesses symptom severity on a 5-Likert scale, where "0" represents "not at all" and "4" represents "extremely." There are nine symptoms included in the instrument: somatization, obsessive compulsive, interpersonal sensitivity, hostility, depression, anxiety, paranoid ideation, phobic anxiety, and psychoticism. The Thai version of SCL-90 was developed by Chooprayoon ${ }^{30}$ and has been used on both a clinical and nonclinical population. In this study, only somatization was used. The tool has been shown to have a good Cronbach's alpha of 0.92 . For the somatization subscale, a Cronbach's alpha of 0.85 has been generated using this instrument. ${ }^{10}$

\section{The 16 PF}

The $16 \mathrm{PF}$, as developed by Cattell et al, ${ }^{31}$ is a tool used for assessing personality based on eight dimensions or 16 characteristics: warmth, intellect, emotional stability, dominance, liveliness, rule-consciousness, social boldness, sensitivity, vigilance, abstractedness, privateness, apprehensiveness, openness to change, self-reliance, perfectionism, and tension. The $16 \mathrm{PF}$ has 187 items with three choices for each item. The results are rated by giving a score of 1 or 2 , then comparing the results with a standard score. It has been shown to have adequate reliability: Cronbach 0.80 over a 2 -week period and 0.70 over a 2 -month period. ${ }^{32}$ The Thai version of 16 PF was developed by Cheuaphakdi and Phornphatkul, ${ }^{33}$ and has been widely used to assess personality and its relationship to clinical samples. The $16 \mathrm{PF}$ tool is also commonly used among organizations for personnel selection purposes. The Cronbach's alpha found when using the tool in this study ranged between 0.61 and $0.88 .^{33}$

\section{Statistical analysis}

In this study, descriptive statistics were examined across all variables. The continuous scores of each variable were used for analysis. Path analysis using AMOS 18 (IBM Corporation, Armonk, NY, USA) was applied to establish the effects of the personality trait predictors as well as the outcomes (somatization and social inhibition). A graphical illustration of path analysis is an easy, convenient, and effective way to present the complicated relationships among variables that exist as it allows one to see the influence of personality traits on somatization and social inhibition at the same time, and also the indirect effect of personality traits or social inhibition on somatization. 
In the first step, we analyzed the direct effects of the significant, correlated demographic variables, plus each personality trait variable, on somatization and social inhibition, after which we introduced mediator variables and estimated the direct and indirect effects. Path analysis was undertaken using the maximum-likelihood estimation method with all single indicators allowed to be correlated. Two fit indices commonly used in the confirmatory factor analysis literature were used to evaluate the model fit, these being the goodness of fit index $(\mathrm{GFI})^{34}$ and the comparative fit index (CFI) ${ }^{35}$ The root mean square error of approximation (RMSEA) and standardized root-mean-square residual (SRMR) methods were also used as this is an evaluation statistic that is relatively unaffected by sample size and is suitable for assessing models of differing complexity. ${ }^{35,36}$ Modification indices were also applied.

\section{Results}

The age of the participants ranged from 60 to 93 years ( mean $=71.7$; standard deviation $[\mathrm{SD}]=6.7$ ); $50.8 \%$ of the group were male and $54.8 \%$ were married. The average number of years spent in education among the participants was $7.6(\mathrm{SD}=5.2)$. Out of the 16 personality factors, only seven personality traits significantly related to either social inhibition or somatization were selected: emotional stability, dominance, reasoning, vigilance, apprehension, self-reliance, and tension (Table 1).

Table 2 shows the correlation coefficients between variables. Vigilance was found to correlate with both social inhibition and somatization $(r=0.229, P<0.001$ and $r=0.192$, $P<0.05$, respectively). The other personality traits correlated in the range of 0.185 to -0.267 . Personality traits revealing significant correlations with social inhibition and somatization were included in the hypothesized model.

Table I Descriptive statistics of the sample $(n=\mid 26)$

\begin{tabular}{lll}
\hline Variables & Mean (min-max) & SD \\
\hline Age (years) & $71.72(60-93)$ & 6.72 \\
Education (years) & $7.6 I(0-22)$ & 5.16 \\
Income (units/month)* & $2.02(I-9)$ & 1.71 \\
Somatization & $0.83(0-2.3)$ & 0.59 \\
Social inhibition & $16.21(0-30)$ & 6.13 \\
Personality traits & & \\
$\quad$ Emotional stability & $4.28(I-8)$ & 1.49 \\
Dominance & $4.65(I-9)$ & 1.57 \\
Reasoning & $4.46(I-9)$ & 1.87 \\
Vigilance & $6.93(2-10)$ & 1.61 \\
$\quad$ Apprehension & $6.79(I-10)$ & 1.60 \\
Self-reliance & $5.63(I-10)$ & 1.64 \\
Tension & $5.63(I-10)$ & 1.64 \\
\hline
\end{tabular}

Note: $*$ I unit $=5,000$ baht (approximately 167 US dollars).

Abbreviations: min, minimum; max, maximum; SD, standard deviation.
Figure 2 shows the final path analysis model. Sex, reasoning, apprehension, and self-reliance were excluded from the model as they yielded low estimates in terms of regression weighting $(P \geq 0.05)$. As a result, only emotional stability, dominance, and vigilance were retained. However, the direct effect of age on social inhibition, dominance on social inhibition, and social inhibition on somatization was not significant $(P>0.05)$, so these three paths were deleted from the model.

Figure 3 shows that all the hypothesized paths in the final model were significant. Age was found to have a direct impact only on somatization ( $\beta=0.25, z=3.20, P=0.001$ ), and then indirectly on social inhibition via the education level as they were significantly correlated $(r=-0.37)$. A lower education level was shown to have a direct association with high levels of somatization $(\beta=-0.37, z=-4.80, P<0.001)$ as well as social inhibition $(\beta=-0.19, z=-2.17, P=0.03)$. Emotional stability had a direct effect on both somatization $(\beta=-0.19, z=-2.58, P=0.01)$ and social inhibition $(\beta=-0.19$, $z=-2.27, P=0.023)$. Dominance had an effect on somatization $(\beta=0.18, z=-2.45, P=0.014)$ and a direct effect on vigilance $(\beta=0.33, z=3.86, P<0.001)$, and vigilance had an effect on social inhibition $(\beta=0.19, z=2.50, P=0.024)$. The indirect effect of dominance on social inhibition produced a score of 0.062 . More importantly, modification indices did not suggest a link between social inhibition and somatization, as had been speculated beforehand. ${ }^{18,25}$ The $R^{2}$ for somatization was 0.35 , whereas for social inhibition it was 0.10 . The model showed a very good fit to the data, with $\chi^{2}=3.55, d f=6, P=0.738, \mathrm{CFI}=1.00, \mathrm{TLI}=1.097, \mathrm{NFI}=0.968$, GFI $=0.992$, RMSEA $=0.00$, and $\mathrm{SRMR}=0.031$, and all paths were significant $(P<0.05)$.

\section{Discussion}

To our knowledge, this is the first study investigating the link between personality traits and both somatization and social inhibition at the same time. Above all, age and education were found to have an effect on both symptoms, with education found to have the strongest influence when compared to personality traits. This result may have been due to the level of intelligence of the individuals involved, as found in previous studies. ${ }^{37-39}$ Age was found to have both a direct and indirect impact on these symptoms when combined with personality traits.

As mentioned earlier, here emotional stability was found to be related separately to both somatization and social inhibition. Our model showed that it had an impact on both outcomes, meaning that elderly people in the study who had a 
Table 2 Correlation matrix between the selected personality traits and the demographic and dependent variables

\begin{tabular}{|c|c|c|c|c|c|c|c|c|c|c|c|c|c|}
\hline & & I & 2 & 3 & 4 & 5 & 6 & 7 & 10 & 14 & 17 & 19 & 21 \\
\hline I & Sex & I & & & & & & & & & & & \\
\hline 2 & Age & 0.015 & I & & & & & & & & & & \\
\hline 3 & Education & -0.020 & $-0.365 * *$ & I & & & & & & & & & \\
\hline 4 & Somatization & 0.165 & $0.404 * *$ & $-0.467 * *$ & 1 & & & & & & & & \\
\hline 5 & Social inhibition & -0.037 & 0.091 & -0.174 & $0.256 * *$ & I & & & & & & & \\
\hline 6 & $\begin{array}{l}\text { Emotional } \\
\text { stability }\end{array}$ & 0.108 & 0.011 & -0.086 & -0.151 & $-0.196 *$ & 1 & & & & & & \\
\hline 7 & Dominance & $0.178^{*}$ & 0.113 & -0.111 & $0.243 * *$ & 0.067 & 0.012 & I & & & & & \\
\hline 10 & Reasoning & -0.064 & -0.104 & $0.242^{* *}$ & $-0.267^{* *}$ & -0.074 & 0.003 & $-0.189 *$ & I & & & & \\
\hline 14 & Vigilance & 0.113 & 0.050 & -0.038 & $0.192 *$ & $0.229 * *$ & -0.107 & $0.326 * *$ & $-0.275^{* *}$ & I & & & \\
\hline 17 & Apprehension & -0.121 & 0.045 & $-0.280 * *$ & $0.185 *$ & 0.009 & $-0.259 * *$ & 0.057 & $-0.176^{*}$ & 0.096 & 1 & & \\
\hline 19 & Self-reliance & -0.004 & 0.000 & 0.146 & 0.002 & $0.196 *$ & -0.061 & 0.043 & 0.019 & 0.053 & -0.168 & I & \\
\hline 21 & Tension & $-0.243^{* *}$ & $0.192^{*}$ & -0.127 & $0.188^{*}$ & 0.149 & $-0.186^{*}$ & 0.165 & 0.033 & $0.200 *$ & $0.292 * *$ & -0.073 & 1 \\
\hline
\end{tabular}

Notes: *Denotes that the correlation is significant at the 0.05 level (2-tailed); **denotes that the correlation is significant at the 0.01 level $(2$-tailed).

low emotional stability score tended to have both symptoms. Dominance, meanwhile, was found to have a direct effect on somatization and an indirect effect on social inhibition. It is important to note that without the presence of the dominance trait and other factors in the model, emotional stability had no significant effect on somatization. This may be explained by the fact that somatization is related to depression, that is, it may be influenced by depression, which in turn is related to neuroticism (or inverse emotional stability). ${ }^{40-46}$ Neitzert et al compared the relationships between neuroticism, depression, and somatic symptoms in a healthy student sample, finding that neuroticism and depression are significantly and positively related to somatic symptoms reporting, even after controlling for the effects of neuroticism. ${ }^{47}$ However, our study

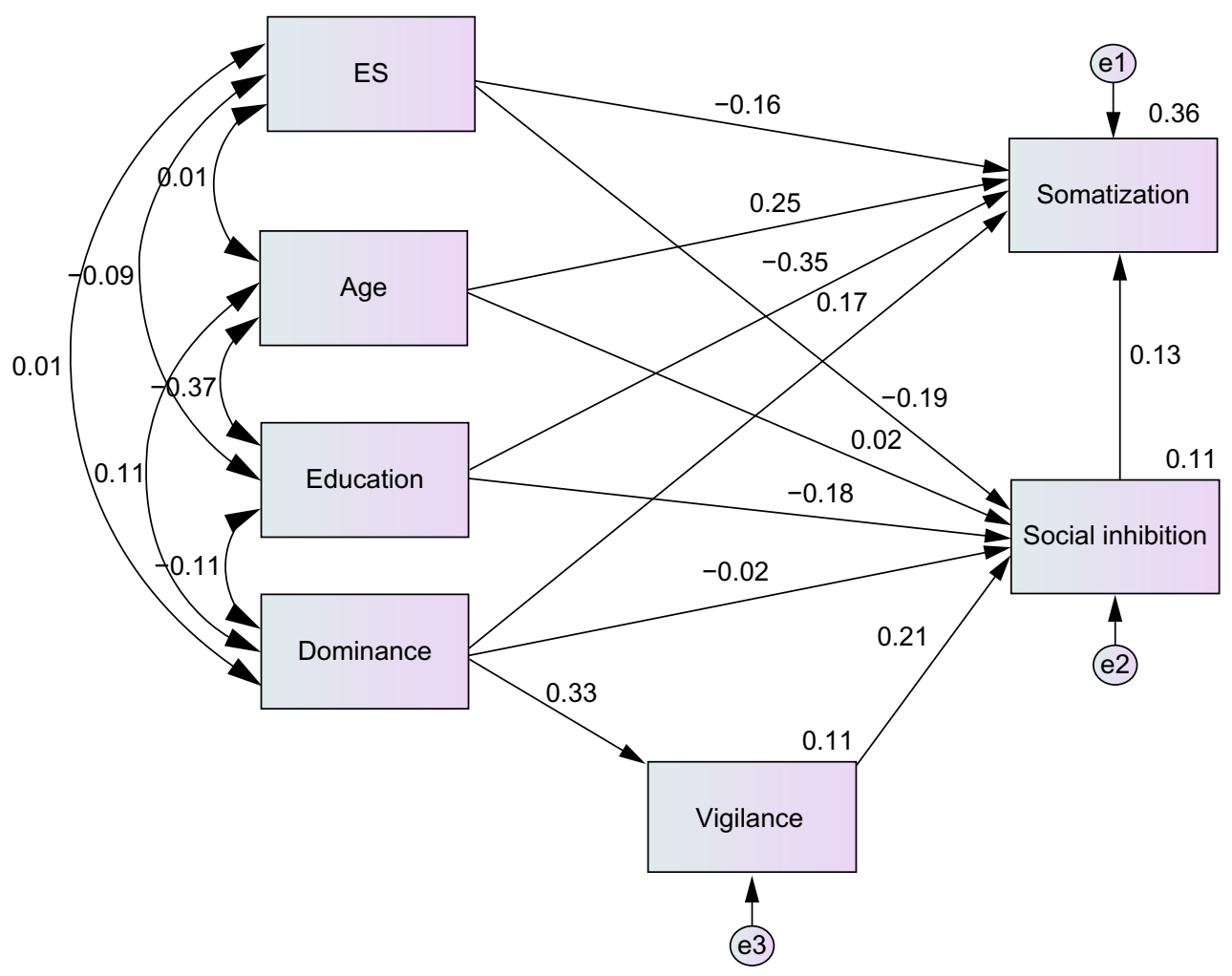

Figure 2 Path model for somatization and social inhibition with $\beta$ and $R^{2}$ as coefficients.

Notes: $\beta$ = standardized regression coefficients which constitute the effect of one variable on another when other variables are controlled. $R^{2}=$ squared multiple correlation coefficients which constitute the amount of variance the predictor variables explain in the observed variable.

Abbreviations: ES, emotional stability; el, error terms of somatization; e2, error terms of social inhibition; e3, error terms of vigilance. 


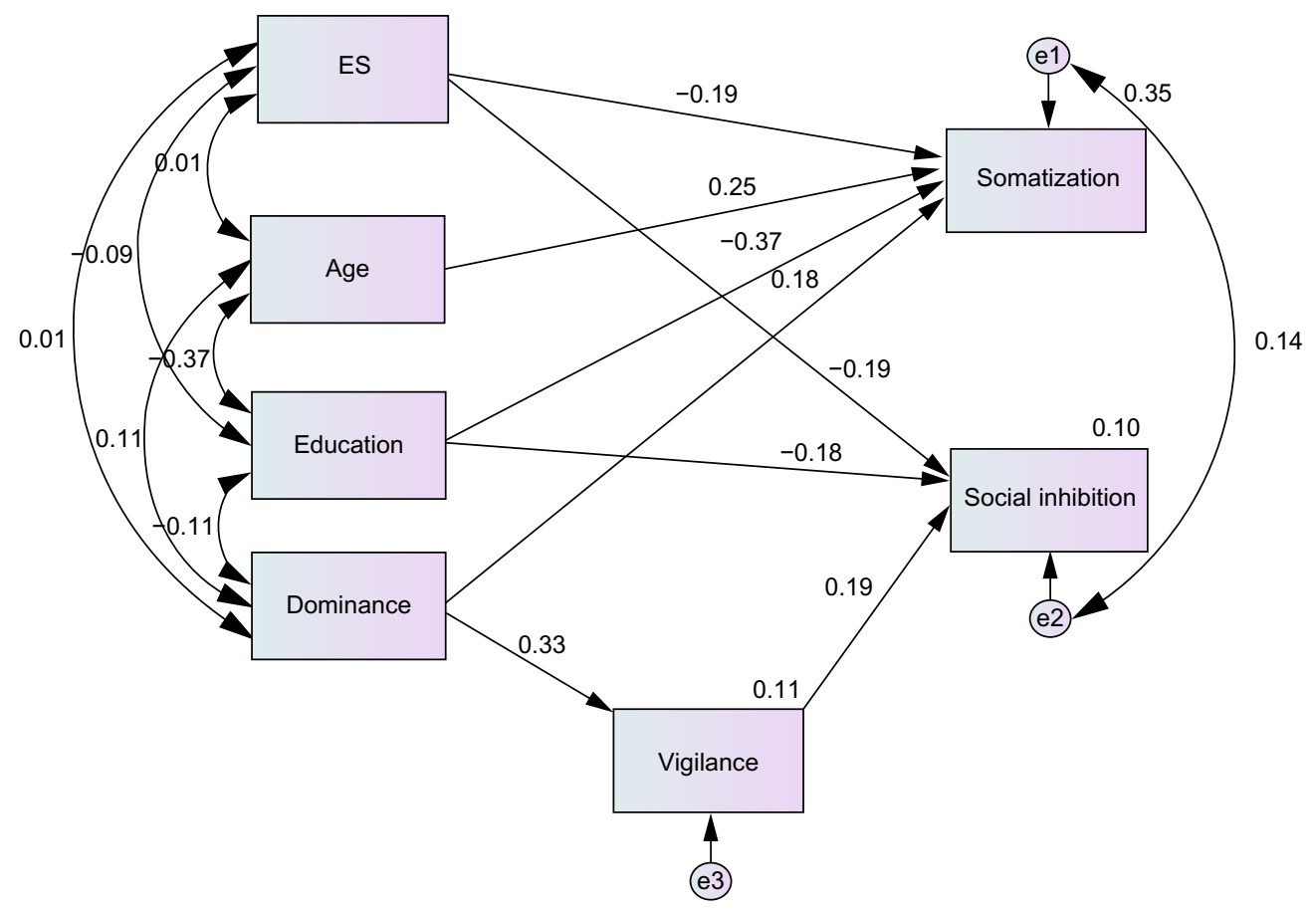

Figure 3 Path model for somatization and social inhibition with $\beta$ and $R^{2}$ as coefficients (final model).

Notes: $\beta=$ standardized regression coefficients which constitute the effect of one variable on another when other variables are controlled. $R^{2}=$ squared multiple correlation coefficients which constitute the amount of variance the predictor variables explain in the observed variable.

Abbreviations: ES, emotional stability; el, error terms of somatization; e2, error terms of social inhibition; e3, error terms of vigilance.

focused exclusively on the importance of personality traits with regard to social inhibition and somatization when depression is not involved, which is why the effect of emotional stability was not dramatic.

It is interesting to note that somatization is related to dominance, which is defined by the presence of characteristics such as assertiveness, forcefulness, aggressiveness, and competiveness. What can be understood from this relationship between dominance and somatization? Some assumptions we would like to make here are that since the dominance personality trait is forceful - an assertive personality akin to a Type A - it has been found to be related to a narcissistic personality. ${ }^{48}$ It may therefore be speculated that sociocultural influences have a role to play, particularly among the Thai elderly, with regard to the dominance personality trait. In Thai society, older people tend to feel powerless and that they lack authority. ${ }^{49}$ They tend to submit and expect not be independent, and this undermines their pride and self-esteem. When compared to younger people with these personality types, it may be rather difficult for dominant elderly people to assert themselves, or to express their frustrations, meaning that somatic complaints may reflect an idiom of distress. Dominance indirectly endorses social inhibition through the suspicion trait, while skepticism (vigilance) may make an older person socially withdraw rather than step forward for help in a time of need, as the elderly are expected by Thai society to be knowledgeable and self-fulfilled.

As for social inhibition, there is evidence that it has a relationship with emotional stability, ${ }^{23}$ in contrast to the findings of Kingma et al who found that neuroticism had no effect on social inhibition. ${ }^{50}$ This can be attributed to the fact that there were differences in terms of the neuroticism-related outcomes measured and instruments used in these studies. It is interesting to note that the results here showed no direct effect of social inhibition on somatization, as had been hypothesized in the model, even though both social inhibition and somatization are significantly correlated. In fact, social inhibition did have a significant effect on somatization, but this was reduced to a nonsignificant level when other personality traits were included. This suggests that these personality traits outweigh the effect social inhibition has on somatization. To summarize, somatization symptoms, without depression, were related to (instead of being influenced by) social inhibition and both were influenced by age, education level, as well as inverse emotional stability, dominance, and vigilance personality traits. What outcomes here are of use when dealing with elderly people experiencing somatization and social inhibition, but without depression? The model used here suggests we should consider an individual's level of 
education (or intelligence), his or her age, and also look out for the personality traits of emotional stability (or neuroticism), dominance, and vigilance. To help patients feel safe, therapists should reduce the level of fear and anxiety patients experience, while creating a way for them to express their self-esteem and pride. Approaching the problems in this way should help them to cope with stress or frustrations better rather than avoiding their problems and using somatic complaints as a way to cope with stress or frustration. In addition, building trust should help improve their socialization levels, which in turn may prevent them experiencing somatic preoccupation.

\section{Limitations}

Several limitations should be noted. First, the sample size used in this study was rather small, and this will have had an impact on the statistical analyses. Second, this study investigated a nonclinically diagnosed sample of somatization sufferers using the SCL-90 self-reporting tool, whereas ideally, clinician rated structured interviews should have been used to assess the presence or otherwise of the condition. Third, this study was cross-sectional in nature, therefore it was not possible to evaluate causality.

\section{Conclusion}

Our study identified personality traits and sociodemographic variables that have an effect on somatization and social inhibition. Emotional stability, dominance, and vigilance, as well as age and level of education were found to have an effect on these symptoms. Therefore, primary care workers should perhaps pay more attention to these factors when dealing with elderly with somatization. However, further studies with larger sample size and longitudinal design is encouraged to warrant the likelihood of the model. In addition, the authors encourage investigating how depression has its effect on these variables in any further study.

\section{Author contributions}

TW and NW conceived and designed the research. TW was responsible for the statistical analysis. Both authors contributed toward drafting and revising the manuscript and have approved the final version.

\section{Acknowledgments}

The authors are grateful to the Faculty of Medicine at Chiang Mai University for having provided funding support.

\section{Disclosure}

The authors report no conflicts of interest in this work.

\section{References}

1. Chakraborty K, Avasthi A, Grover S, Kumar S. Functional somatic complaints in depression: An overview. Asian J Psychiatr. 2010;3(3): 99-107.

2. Chakraborty K, Avasthi A, Kumar S, Grover S. Psychological and clinical correlates of functional somatic complaints in depression. Int J Soc Psychiatry. 2012;58(1):87-95.

3. Frangos E, Zekry D, Rudhard-Thomazic V, Giardini U, J Perrenoud JJ. Somatic complaints in psychiatric elderly patients: Three clinical cases. Eur Geriatr Med. 2011;2:31-34.

4. Hilderink PH, Benraad CE, van Driel D, et al. Medically unexplained physical symptoms in elderly people: a pilot study of psychiatric geriatric characteristics. Am J Geriatr Psychiatry. 2009; 17(12):1085-1088.

5. Sheehan B, Bass C, Briggs R, Jacoby R. Do general practitioners believe that their older patients physical symptoms are somatized? JPsychosom Res. 2004;56(3):313-316.

6. Löwe B, Spitzer RL, Williams JB, Mussell M, Schellberg D, Kroenke K. Depression, anxiety and somatization in primary care: syndrome overlap and functional impairment. Gen Hosp Psychiatry. 2008;30(3): 191-199.

7. Wongpakaran N, Wongpakaran T. Prevalence of major depressive disorders and suicide in long-term care facilities: a report from northern Thailand. Psychogeriatrics. 2012;12(1):11-17.

8. Nguyen HT, Zonderman AB. Relationship between age and aspects of depression: consistency and reliability across two longitudinal studies. Psychol Aging. 2006;21(1):119-126.

9. Fiske A, Wetherell J, Gatz M. Depression in older adults. Annu Rev Clin Psychol. 2009;5:363-389.

10. Wongpakaran T, Wongpakaran N, Boripuntakul T. Symptom checklist-90 (SCL-90) in a Thai sample. JMed Assoc Thai. 2011;94(9): 1141-1149.

11. Aragona M, Monteduro DM, Colosimo F, Maisano B, Geraci S. Effect of gender and marital status on somatization symptoms of immigrants from various ethnic groups attending a primary care service. Ger $J$ Psychiatr. 2008:64-72.

12. Aragona M, Rovetta E, Pucci D, Spoto J, Villa AM. Somatization in a primary care service for immigrants. Ethn Health. 2012;17(5):477-491.

13. Suen LJ, Tusaie K. Is somatization a significant depressive symptom in older Taiwanese Americans? Geriatr Nurs. 2004;25(3):157-163.

14. Klimowicz A. [Comparison of the personality of anxiety disorder patients and somatization disorder patients before and after psychotherapy]. Psychiatr Pol. 2003;37(2):235-246. Polish.

15. De Gucht V. Stability of neuroticism and alexithymia in somatization. Compr Psychiatry. 2003;44(6):466-471.

16. Sifneos PE. Alexithymia: past and present. Am J Psychiatry. 1996; 153(Suppl 7):137-142.

17. Monsen K, Havik O. Psychological functioning and bodily conditions in patients with pain disorder associated with psychological factors. Br J Med Psychol. 2001;74(Pt 2):183-195.

18. Sar V, Akyüz G, Kundakçi T, Kiziltan E, Dogan O. Childhood trauma, dissociation, and psychiatric comorbidity in patients with conversion disorder. Am J Psychiatry. 2004;161(12):2271-2276.

19. Jellesma FC. Health in young people: social inhibition and negative affect and their relationship with self-reported somatic complaints. J Dev Behav Pediatr. 2008;29(2):94-100.

20. Cheng ST, Chan AC. Withdrawal, apathy and lack of vigor in late life depression: factorial validity and relationship to diagnosis. Aging Ment Health. 2007;11(5):532-537.

21. Lee SH, Wen MC, Chao CC, Chen YJ, Yen CF. Apathy in late-life depression among Taiwanese patients. Int Psychogeriatr. 2008;20(2): 328-337.

22. Wen MC, Lee SH. Apathy is a syndrome of executive dysfunction that exists in patients with late-life depression. Int Psychogeriatr. 2009; 21(1):205-206. 
23. Wongpakaran N, Wongpakaran T, van Reekum R. Social inhibition as a mediator of neuroticism and depression in the elderly. BMC Geriatr. 2012;12(1):41.

24. Eysenck HJ. Dimensions of personality: 16, 5, or 3 ? - criteria for a taxonomic paradigm. Pers Individ Diff. 1991;12(8):773-790.

25. McCrae RR, Costa PT. Validation of the five factor model of personality across instruments and observers. J Pers Soc Psychol. 1987:81-90.

26. Denollet J. Personality and coronary heart disease: the type-D scale-16 (DS16). Ann Behav Med. 1998;20(3):209-215.

27. Wongpakaran T, Wongpakaran N, Sirithepthawee U, et al. Interpersonal problems among psychiatric outpatients and non-clinical samples. Singapore Med J. 2012;53(7):481-487.

28. Alden L, Wiggins J, Pincus A. Construction of circumplex scales for the Inventory of Interpersonal Problems. J Pers Assess. 1990;55(3-4): 521-536.

29. Derogatis L, Lipman R, Covi L. SCL-90: an outpatient psychiatric rating scale - preliminary report. Psychopharmacol Bull. 1973;9(1):13-28.

30. Chooprayoon L. SCL-90 in neurotic patients. J Clin Psychol. 1977;9(2):9-16.

31. Cattell RB, Eber HW, Tatsuoka MM. The Handbook for the Sixteen Personality Factor Questionnaire (16 PF). Champaign (IL): Institute for Personality Ability Testing; 1970.

32. Cattell HEP, Mead AD. The sixteen personality factor questionnaire (16PF). In: Boyle GJ, Matthews G, Saklofske DH, editors. The SAGE Handbook of Personality Theory and Assessment: Personality Measurement and Testing. London: SAGE Publications Ltd; 2008;2: 135-159.

33. Cheuaphakdi P, Phornphatkul S. The relationship between personality and work outcome among nurses in Siriraj Hospital. Bangkok, Mahidol; 1983.

34. Jöreskog KG, Sörbom D. LISREL IV: Analysis of Linear Structural Relationships by Maximum Likelihood, Instrumental Variables, and Least Squares Methods. 3rd ed. Mooresville (IN): Scientific Software; 1984.

35. Hu L, Bentler PM. Evaluating model fit. In: Hoyle RH, editor. Structural Equation Modeling: Concepts, Issues and Applications. Thousand Oaks (CA): Sage Publications, Inc; 1995:76-99.

36. $\mathrm{Hu} \mathrm{L}$, Bentler PM. Fit indices in covariance structure modeling: Sensitivity to under parameterized model misspecification. Psychol Methods. 1998;3:424-453.

37. Bøen H, Dalgard OS, Bjertness E. The importance of social support in the associations between psychological distress and somatic health problems and socio-economic factors among older adults living at home: a cross sectional study. BMC Geriatr. 2012;12:27.
38. Watt T, Groenvold M, Bjorner JB, Noerholm V, Rasmussen NA, Bech P. Fatigue in the Danish general population. Influence of sociodemographic factors and disease. J Epidemiol Community Health. 2000; 54(11):827-833.

39. Kingma EM, Tak LM, Huisman M, Rosmalen JG. Intelligence is negatively associated with the number of functional somatic symptoms. J Epidemiol Community Health. 2009;63(11):900-905.

40. Pearson K, Watkins E, Mullan E. Submissive interpersonal style mediates the effect of brooding on future depressive symptoms. Behav Res Ther. 2010;48(10):966-973.

41. Duberstein P, Pálsson S, Waern M, Skoog I. Personality and risk for depression in a birth cohort of 70-year-olds followed for 15 years. Psychol Med. 2008;38(5):663-671.

42. Sneed J, Kasen S, Cohen P. Early-life risk factors for late-onset depression. Int J Geriatr Psychiatry. 2007;22(7):663-667.

43. Steunenberg B, Beekman A, Deeg D, Kerkhof A. Personality and the onset of depression in late life. J Affect Disord. 2006;92(2-3): 243-251.

44. Steunenberg B, Beekman A, Deeg D, Kerkhof A. Personality predicts recurrence of late-life depression. J Affect Disord. 2010;123(1-3): 164-172.

45. Uluşahin A, Uluğ B. Clinical and personality correlates of outcome in depressive disorders in a Turkish sample. J Affect Disord. 1997;42(1):1-8.

46. Hutchinson JG, Williams PG. Neuroticism, daily hassles, and depressive symptoms: An examination of moderating and mediating effects. Pers Indiv Diff. 2007;42:1367-1378.

47. Neitzert CS, Davis C, Kennedy SH. Personality factors related to the prevalence of somatic symptoms and medical complaints in a healthy student population. Br J Med Psychol. 1997;70(Pt 1):93-101.

48. Fukunishi I, Moroji T, Okabe S. Stress in middle-aged women: influence of Type A behavior and narcissism. Psychother Psychosom. 1995;63(3-4):159-164.

49. Thanakwang K. Social relationships influencing positive perceived health among Thai older persons: a secondary data analysis using the National Elderly Survey. Nurs Health Sci. 2009;11(2):144-149.

50. Kingma EM, de Jonge P, Ormel J, Rosmalen JG. Predictors of a functional somatic syndrome diagnosis in patients with persistent functional somatic symptoms. Int J Behav Med. 2013;20(2):206-212.
Clinical Interventions in Aging

\section{Publish your work in this journal}

Clinical Interventions in Aging is an international, peer-reviewed journal focusing on evidence-based reports on the value or lack thereof of treatments intended to prevent or delay the onset of maladaptive correlates of aging in human beings. This journal is indexed on PubMed Central, MedLine, the American Chemical Society's 'Chemical Abstracts

\section{Dovepress}

Service' (CAS), Scopus and the Elsevier Bibliographic databases. The manuscript management system is completely online and includes a very quick and fair peer-review system, which is all easy to use. Visit http://www.dovepress.com/testimonials.php to read real quotes from published authors. 